Tropical Journal of Pharmaceutical Research January 2017; 16 (1): 3-8

ISSN: $1596-5996$ (print); 1596-9827 (electronic)

(C) Pharmacotherapy Group, Faculty of Pharmacy, University of Benin, Benin City, 300001 Nigeria.

All rights reserved.

Available online at http://www.tjpr.org

Original Research Article

http://dx.doi.org/10.4314/tjpr.v16i1.2

\title{
Development of an in situ polymeric hydrogel implant of methylprednisolone for spinal injuries
}

\author{
Ting-Jin Guan ${ }^{1 *}$, Qing-Hua $\mathrm{Zhu}^{2}$, Xiao $\mathrm{Ma}^{3}$ and Ming Ding ${ }^{1}$ \\ ${ }^{1}$ Department of Orthopaedics, ${ }^{2}$ Department of Surgery, The First Hospital of Zibo City Affiliated to Weifang Medical College, \\ Zibo 255200, ${ }^{3}$ Weifang Medical College, Weifang 261053, Shandong, China \\ *For correspondence: Email: guantingjin@hotmail.com; Tel/Fax: 0086-533-4198088
}

Revised accepted: 1 December 2016

\begin{abstract}
Purpose: To prepare and characterize in situ gel-forming implants of methylprednisolone for the treatment of spinal cord injuries.

Methods: In situ hydrogels of methylprednisolone were prepared by dispersing polylactide glycolic acid (PLGA) polymer and methylprednisolone in N-methyl-pyrrolidone solvent, and subsequent membrane sterilization. Hydrogels were prepared using varying concentrations of PLGA polymer. The physicochemical properties of hydrogels, including visual appearance, clarity, $\mathrm{pH}$, viscosity, drug content, and in vitro drug release, were characterized. In vivo studies were performed to examine antiinflammatory activity (paw edema test) and in vivo motor function activity in a rat spinal injury model after injecting the hydrogels into rats.

Results: The physicochemical properties of the gels were satisfactory. F1, F2, F3, and F4 formulations showed 99.67, 95.29, 88.89 and $88.20 \%$ drug release, respectively, at the end of 7 days. In vivo antiinflammatory activity was highest for $\mathrm{F1}(62.85 \%)$. Motor function activity scores (arbitrary scale) for the $F 1, F 2, F 3$ and F4 formulations were $4.82 \pm 0.12,4.70 \pm 0.12,4.68 \pm 0.02$, and $4.60 \pm 0.05$, respectively, and were higher $(p<0.05)$ for $F 1, F 2$ and $F 3)$ than for the standard (methylprednisolone, $30 \mathrm{mg} / \mathrm{kg}$ body weight, iv; activity score, $4.59 \pm 0.20$ ).

Conclusions: The in situ hydrogels of methylprednisolone developed may be useful for the effective management of spinal cord injuries in patients. However, further investigations are required to ascertain their suitability for clinical use.
\end{abstract}

Keywords: Methy/prednisolone, In situ hydrogel, Spinal injury, Motor activity, Implant

Tropical Journal of Pharmaceutical Research is indexed by Science Citation Index (SciSearch), Scopus, International Pharmaceutical Abstract, Chemical Abstracts, Embase, Index Copernicus, EBSCO, African Index Medicus, JournalSeek, Journal Citation Reports/Science Edition, Directory of Open Access Journals (DOAJ), African Journal Online, Bioline International, Open-J-Gate and Pharmacy Abstracts

\section{INTRODUCTION}

Spinal cord injury $(\mathrm{SCl})$ can lead to permanent disability and decreased life expectancy. The primary injury (local damage to tissues) is followed by secondary injuries (neuropathic pain, inflammation, reversible and/or irreversible damage to the nervous system), making $\mathrm{SCl}$ difficult to manage [1-4]. The management of pain and inflammation is achieved using various analgesics and anti-inflammatory agents, including opioids, non-steroidal anti-inflammatory drugs, muscle relaxants, and steroids [4-6].

Acute steroid administration has been reported to be effective as a first-line therapy, and a high dose of methylprednisolone (MP) immediately after traumatic $\mathrm{SCl}$ is well accepted as a standard treatment $[6,7]$. MP is a potent antiinflammatory glucocorticoid. It leads to significant recovery from primary tissue damage and secondary neuropathic pain and inflammation in $\mathrm{SCl}$. MP use has been reported to significantly 
improve motor nerve activity in cases of $\mathrm{SCl}$ [810].

Although several studies have documented significant positive effects of MP (when administered intravenously) in $\mathrm{SCl}$, many drugs used for the treatment of this condition cannot cross the blood-spinal cord barrier. Thus, neither oral nor intravenous delivery provides the optimal desired benefit of neuroprotective or neuroregenerative drugs. The physical inaccessibility of the spinal cord is usually dealt with using alternative measures, such as local epidural or intrathecal delivery (by bolus injection or catheter/implant insertion) [11,12]. The delivery of drugs to the microenvironment of the spinal cord through intrathecal administration in polymeric hydrogels and in situ has been reported to be promising in $\mathrm{SCl}$, with advantages including improved safety, prolonged delivery (up to 4 weeks), and reduced dosage (frequency) [13-15].

Implants that are formed from polymeric gels or solutions containing drugs undergo chemical or physical changes to form unit implants for controlled drug delivery when injected into the body. Dunn et al [16] were pioneers in the development of in situ implants. Injectable in situ implants of antibiotics were prepared for the local treatment of periodontitis. These systems form implants in situ with changes in factors such as temperature, $\mathrm{pH}$, ionic crosslinking, and solvent removal. Among the various techniques, in situ solvent removal systems have been investigated for the delivery of drugs such as leuprolide acetate (Luteinizing hormone releasing hormone or LHRH agonist) in prostate cancer management, using $\mathrm{N}$-methyl-pyrrolidone (NMP) as the solvent $[17,18]$.

The present study concerns the preparation of an in situ hydrogel of MP with polylactide glycolic acid (PLGA) using NMP as a biocompatible solvent (class 2 solvent in the International Conference on Harmonization $(\mathrm{ICH})$ guidelines, with no inflammatory property in biological systems) [19]. NMP is a common organic solvent used in the preparation of in situ PLGA implants. In an in situ solvent removal system, MP is converted to a gel upon contact with the aqueous environment of biological fluids. Immediately after contact with the aqueous environment, the NMP diffuses out rapidly, leading to rapid polymer precipitation. This process ultimately results in the formation of a porous polymer matrix, which then slowly releases the drug [20]. In situ gels can be used for local and systemic controlled drug delivery [14,15,21-23]. Here, we describe the development of a polymeric in situ hydrogel of MP for intrathecal delivery to improve neuroprotective and neuroregenerative effects in $\mathrm{SCl}$.

\section{EXPERIMENTAL}

\section{Materials}

MP succinate, PLGA, and NMP were purchased from Sigma Aldrich, St. Louis, MO, USA). All other chemicals were of analytical grade.

\section{Preparation of polymeric hydrogels of MP}

The in situ solvent removal systems for polymeric hydrogels of MP were prepared using the formulae shown in Table 1.

Table 1: Composition of in situ hydrogels of $1 \%$ (w/w) methylprednisolone

\begin{tabular}{lll}
\hline Implant & $\begin{array}{l}\text { PLGA } \\
(\% \mathbf{w} / \mathbf{w})\end{array}$ & NMP $^{*}$ \\
\hline F1 & 8 & q.s. \\
F2 & 10 & q.s. \\
F3 & 12 & q.s. \\
F4 & 14 & q.s. \\
\hline${ }^{*}$ NMP (N-methyl-2-pyrrolidone) was used as the \\
solvent. PLGA: polylactide glycolic acid.
\end{tabular}

The polymeric solution was prepared with sufficient NMP to dissolve the PLGA at $50^{\circ} \mathrm{C}$, and the solution was then cooled to room temperature $\left(25^{\circ} \mathrm{C}\right)$. The required amount of drug was weighed accurately and then gently dispersed in the polymeric solution with stirring (200 rpm) for $30 \mathrm{~min}$. After degassing, the resulting solution was sterilized by membrane filtration and then stored in a tightly closed glass vial $(10 \mathrm{~mL})$ in a vacuum desiccator.

\section{Physical characterization of the gel implants}

The prepared drug-loaded polymeric solutions were observed to evaluate clarity (visual inspection) and viscosity (Brookfield viscometer).

\section{Drug content determination}

From the vials of the formulations, $1 \mathrm{~mL}$ of each sample was transferred to a volumetric flask using a micropipette. To this sample, methanol (up to $10 \mathrm{~mL}$ ) was added until complete precipitation (i.e., the upper solution became mostly clear). After centrifugation (1000 rpm, 20 min), the clear supernatant sample was withdrawn. The withdrawn sample was analyzed spectrophotometrically at $246 \mathrm{~nm}$ after suitable dilution. 


\section{In vitro drug release studies}

The formulation $(10 \mathrm{~mL})$ was first converted to a hydrogel by mixing with $20 \mathrm{~mL}$ phosphate buffer $(\mathrm{pH}$ 7.4). Due to the removal of NMP, the hydrogel formed; this pre-gelled hydrogel was then used for the in vitro release study. The study was performed by keeping the pregelled formulation in a glass vial containing another 20 $\mathrm{mL}$ phosphate buffer. The vial was kept on a shaker in a water bath at $37 \pm 1{ }^{\circ} \mathrm{C}$ and 50 oscillations $/ \mathrm{min}$. Samples (1 $\mathrm{mL}$ each) were withdrawn at predetermined intervals for 7 days. Each sample was replaced with an equal volume of fresh phosphate buffer. The samples $(n=3)$ were analyzed spectrophotometrically at $246 \mathrm{~nm}$ after suitable dilution.

\section{In vivo study protocols}

Healthy male Wistar rats (weighing $175-250 \mathrm{~g}$ ) were used. The rats were kept in cages in standard environmental conditions of light and temperature. The rats were allowed free access to drinking water and a standard diet. All four formulations were used in the in vivo studies. The animal study protocols were approved by the Animal Care and Use Committee of Weifang Medical College, Zibo (approval ref. no. 2514/10/2014). The in vivo studies were conducted in compliance with directive 2010/63/EU on the handling of animals for scientific purposes.

\section{In vivo anti-inflammatory study}

The formulations were used in an in vivo antiinflammatory study using the standard carrageenan-induced hind rat paw edema model. Rats were divided into eight groups of six rats each (total, 48 rats). Rats in the control group (group I) remained untreated. In groups II-V, test formulations of polymeric in situ gels were injected (30 mg/kg body weight, ip) into the left hind paws of the rats. Group VI received $2 \%$ indomethacin gel (standard). Paw edema was induced at $30 \mathrm{~min}$ after the injection of $0.1 \mathrm{~mL}$ of a $1 \%(\mathrm{w} / \mathrm{v})$ aqueous suspension of carrageenan in the left hind paw in all rats. The left hind paw volume was measured immediately $(0 \mathrm{~h})$ and at subsequent timepoints $(0.5,1,2,4,6,8,10,12$, and $24 \mathrm{~h}$ ) using a plethysmometer, and expressed as percent edema relative to the initial hind paw volume. Percent inhibition of edema was determined and taken as a measure of antiinflammatory activity.

\section{In vivo motor function activity}

In total, 42 rats were used. They were divided into four groups (normal control, negative control, standard, and test), with 6 rats each in first three groups and 24 rats in the test group. The test group was further subdivided into four groups of six rats each for the four formulations. All animals (except those in the normal control group) were subjected to laminectomy by inducing acute spinal injury via extradural 40-g-force clip compression for $10 \mathrm{~s}$ around $\mathrm{T} 7$ after the administration of thiopental sodium $(40 \mathrm{mg} / \mathrm{kg})$. A blank (non-medicated) polymeric solution was administered to normal control rats. The test groups received the drug-loaded polymeric in situ gels $(30 \mathrm{mg} / \mathrm{kg}$ body weight, on the basis of several previous studies) i.t. near the site of the injury. The standard group received MP (30 $\mathrm{mg} / \mathrm{kg}$ body weight) i.v. at 30 min post-injury. The treatment was continued for 1 week. At the end of 7 days, motor functional activity was determined by observing the performance of rats in a horizontal bar experiment. The time period for which the rat could hold the horizontal bar (2$\mathrm{mm}$ diameter) was noted and scores were given.

\section{Statistical analysis}

Results are expressed as means \pm standard deviations. Student's $t$ test was used. $P$ values $<0.05$ were considered to indicate statistical significance.

\section{RESULTS}

On visual inspection, a translucent matrix was formed on addition to phosphate buffer ( $\mathrm{pH}$ 7.4). The prepared in situ hydrogels were transparent at all $\mathrm{pHs}$ tested. The $\mathrm{pHs}$ of all formulations were within the acceptable range (Table 2).

Table 2: Physicochemical characteristics of in situ hydrogels of MP

\begin{tabular}{lcc}
\hline Hydrogel & pH & $\begin{array}{c}\text { Drug } \\
\text { content }\end{array}$ \\
\hline F1 & $6.2 \pm 0.12$ & $99.02 \pm 1.02$ \\
F2 & $6.3 \pm 0.02$ & $100.10 \pm 0.28$ \\
F3 & $6.3 \pm 0.12$ & $99.97 \pm 1.20$ \\
F4 & $6.4 \pm 0.14$ & $100.01 \pm 0.14$ \\
\hline
\end{tabular}

The formulations were colorless with good clarity. The drug content of the formulations ranged from 99.00 to $100.01 \%$ (Table 2).

\section{Rheological properties}

The viscosity of the formulations showed pseudo-plastic rheology, indicated by the shear thinning properties of the formulations. The shear rate increased in direct proportion to the angular velocity in the pregelled formulations. The 
polymeric solutions showed good syringeability and injectability, facilitating administration. The viscosity was dependent on the polymeric content of the formulations (Figure 1).

\section{In vitro drug release}

In vitro drug release studies were carried out for all formulations using phosphate buffer ( $\mathrm{pH}$ 7.4) as the dissolution medium. Drug release values for formulations F1, F2, F3, and F4 were 99.67, $95.29 \%, 88.89$ and 88.20 , respectively, at the end of 7 days (Figure 2).
The formulation with more PLGA showed slower release of the drug at each timepoint, compared with formulations containing less PLGA. This effect was particularly significant in the initial $6 \mathrm{~h}$ for F3 and F4.

\section{In vivo anti-inflammatory activity}

The anti-inflammatory activities of all formulations of the polymeric in situ hydrogel of MP were evaluated in Wistar rats (Table 3 ).

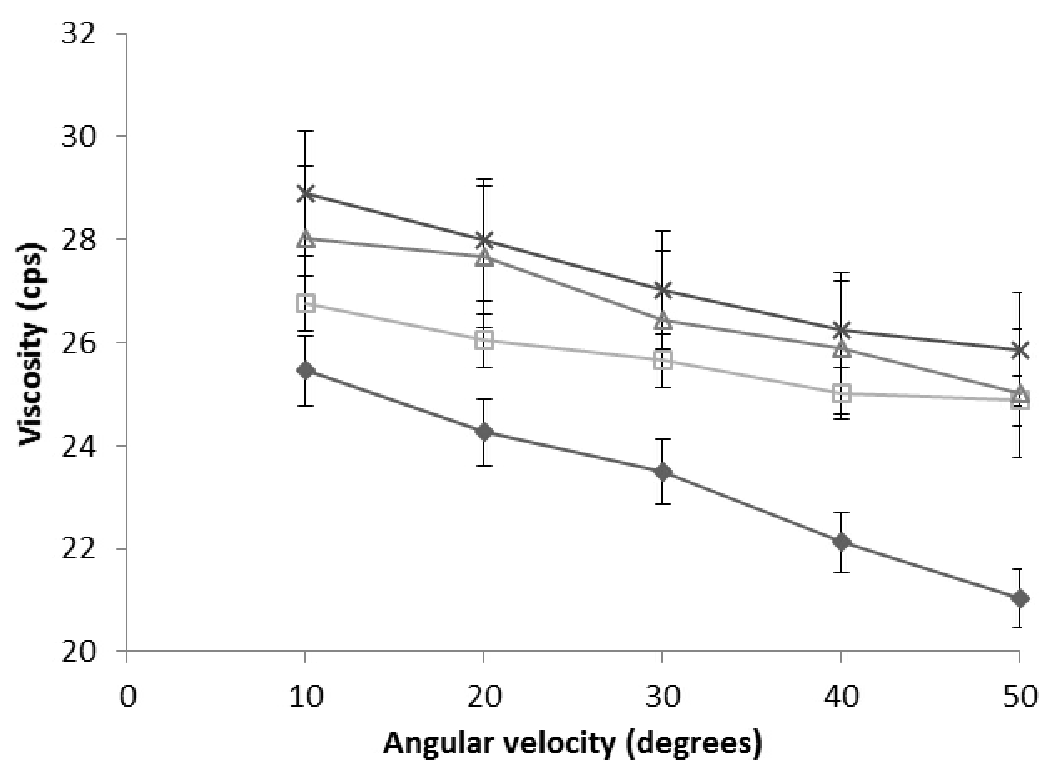

Figure 1: Rhelogical study of pregelled formulations of polymeric in situ hydrogel of methylprednisolone: F1 (^), F2 ( $\square)$, F3 $(\Delta)$, and F4 (×)

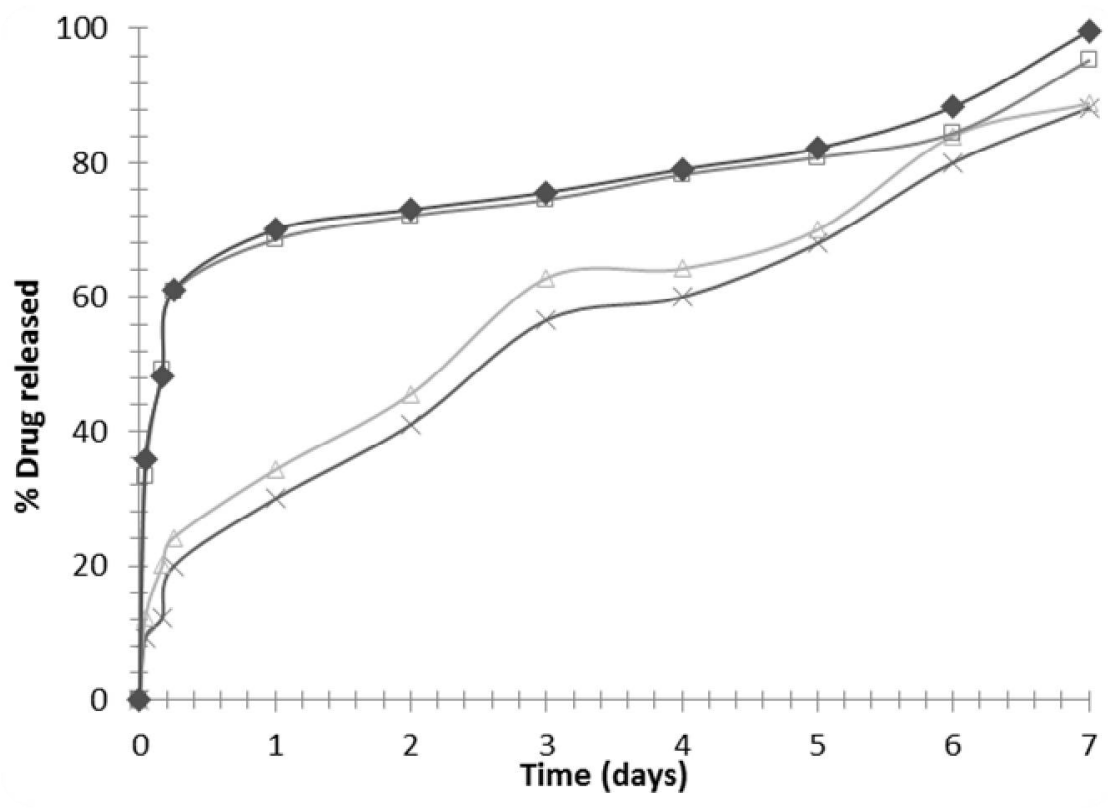

Figure 2: In vitro release of pregelled formulations of polymeric in situ hydrogel of methylprednisolone: F1 (४), F2 ( $\square)$, F3 $(\Delta)$, and F4 (×) 
Table 3: Anti-inflammatory activity of formulations of polymeric in situ hydrogel of methylprednisolone in rats

\begin{tabular}{lcc}
\hline Animal group & \multicolumn{2}{c}{ Anti-inflammatory activity } \\
\cline { 2 - 3 } & $\begin{array}{c}\text { Change in paw volume } \\
(\mathbf{m L})\end{array}$ & $\begin{array}{c}\text { Inhibition of paw } \\
\text { edema (\%) }\end{array}$ \\
\hline Control & $1.05 \pm 0.04^{*}$ & - \\
Standard $(2 \%$ indomethacin gel) & $0.41 \pm 0.45$ & 60.95 \\
F1 & $0.39 \pm 0.12^{\mathrm{a}}$ & 62.85 \\
F2 & $0.40 \pm 1.29^{\mathrm{a}}$ & 61.90 \\
F3 & $0.42 \pm 1.21^{\mathrm{a}}$ & 60.0 \\
F4 & $0.42 \pm 1.01^{\mathrm{a}}$ & 60.0 \\
\hline${ }^{*}$ Mean \pm SEM, $n=6 ;{ }^{* *}$ change in paw volume $12 \mathrm{~h}$ after carrageenan injection; ${ }^{\mathrm{a}} p<0.05$ vs. control
\end{tabular}

Inhibition of paw edema was used as an index of anti-inflammatory activity. It was highest for F1 (62.85\%). The rank order of activity was F1 $>\mathrm{F} 2>\mathrm{F} 3>\mathrm{F} 4$. An in vivo study was also performed to assess the effectiveness of motor nerve activity post-trauma in Wistar rats. The F1 group showed better recovery from spinal injury in terms of improved activity score. Despite showing lesser effects than the other two groups, F3 and F4 showed better activity scores (4.68 \pm 0.02 and $4.60 \pm 0.05$, respectively) than the standard (4.59 \pm 0.20 ; Table 4$)$.

Table 4: In vivo motor function activity of in situ hydrogel of methylprednisolone in a rat spinal injury model

\begin{tabular}{lc}
\hline Group & $\begin{array}{c}\text { Total activity } \\
\text { score }^{\star}\end{array}$ \\
\hline Control (normal) & $8.10 \pm 1.10$ \\
Control (negative) & $0.99 \pm 1.0$ \\
Standard (MP, i.v.) & $4.59 \pm 0.20$ \\
F1 & $4.82 \pm 0.12^{\mathrm{a}}$ \\
F2 & $4.70 \pm 0.12^{\mathrm{a}}$ \\
F3 & $4.68 \pm 0.02^{\mathrm{a}}$ \\
F4 & $4.60 \pm 0.05^{\mathrm{a}}$ \\
\hline${ }^{\mathrm{a}} P<0.05$. &
\end{tabular}

\section{DISCUSSION}

In situ hydrogels of MP showed good drug content and rheological properties, and formulations with higher polymer concentrations showed greater viscosity. The higher-viscosity polymeric formulations showed slower in vitro drug release, likely due to the formation of a stiffer in situ gel. In situ gel stiffness is related positively to the height of is the diffusional barrier faced by the drug. Previous reports showed that higher concentrations of polymer delayed the onset of release from the formulation due to the retardation of polymer precipitation [22-24].

The formulations showed better in vivo performance, indicated by increased anti- inflammatory activity and motor function activity in Wistar rats, compared with the corresponding standards. Formulations F1, F2, F3, and F4 showed in vivo performance in terms of motor function activity according to their polymeric content. Those with higher polymeric content showed less total drug release up to day 7 , so the effects were smaller. However, even the formulation with the least effect (F4) was better than the standard. As the aim of the study was to prepare a prolonged drug delivery system showing a desired effect in SCl, formulations F3 and F4 are the best candidates for further translational studies.

\section{CONCLUSION}

Biodegradable polymers can be used in developing implants as in situ gels of MP for prolonged delivery and effective management of pain and inflammation in SCl. The in situ gels prepared from PLGA using NMP as the solvent showed good in vivo anti-inflammatory activity and effectively improved rat motor function activity. The formulations possessed good physicochemical properties and prolonged drug release, for up to 7 days. Thus, gel implants of MP may be useful as an alternative approach for the effective management of $\mathrm{SCl}$.

\section{ACKNOWLEDGEMENT}

The authors acknowledge The First Hospital of Zibo City and Weifang Medical College, Weifang, for providing facilities for this study.

\section{DECLARATIONS}

\section{Conflict of Interest}

No conflict of interest associated with this work.

\section{Contribution of Authors}

The authors declare that this work was done by 
the authors named in this article and all liabilities pertaining to claims relating to the content of this article will be borne by them.

\section{Open Access}

This is an Open Access article that uses a funding model which does not charge readers or their institutions for access and distributed under the terms of the Creative Commons Attribution License (http://creativecommons.org/licenses/by 14.0) and the Budapest Open Access Initiative (http://www.budapestopenaccessinitiative.org/rea d), which permit unrestricted use, distribution, and reproduction in any medium, provided the original work is properly credited.

\section{REFERENCES}

1. Hagen EM, Rekand T, Gilhus NE, Grønning M. Traumatic spinal cord injuries--incidence, mechanisms and course. Tidsskr Nor Laegeforen.2012; 132: 831-837.

2. Zhang $N$, Yin $Y, X u$ SJ, Wu YP, Chen WS. Inflammation \& apoptosis in spinal cord injury. Indian $\mathrm{J}$ Med Res. 2012; 135(3): 287-296.

3. Whalley K, O'Neill P, Ferretti P. Changes in response to spinal cord injury with development: vascularization, hemorrhage and apoptosis. Neuroscience 2006; 137: 821-832.

4. Thuret S, Moon LD, Gage FH. Therapeutic interventions after spinal cord injury. Nat Rev Neurosci. 2006; 7: 628643.

5. Bracken MB. Steroids for acute spinal cord injury. Cochrane Database Syst Rev. 2012; 1: CD001046

6. Bydon M, Lin J, Macki M, Gokaslan ZL, Bydon A. The current role of steroids in acute spinal cord injury. World Neurosurg. 2014; 82: 848-54

7. Short DJ, El Masry WS, Jones PW. High dose methylprednisolone in the management of acute spinal cord injury - a systematic review from a clinical perspective. Spinal Cord. 2000; 38: 273-286.

8. Kong $X Y$, Gao J, Yang $Y, L i$ YN, Ma WB, Xing B, Wang $R Z$. Research advances in the application of methylprednisolone in the treatment of acute spinal cord injury. Zhongguo Yi Xue Ke Xue Yuan Xue Bao. 2014; 36:680-685

9. Akhtar AZ, Pippin JJ, Sandusky CB. Animal studies in spinal cord injury: a systematic review of methylprednisolone. ATLA 2009; 37: 43-62.

10. Kim DH, Jahng TA. Continuous brain-derived neurotrophic factor (BDNF) infusion after methylprednisolone treatment in severe spinal cord injury. J Korean Med Sci. 2004; 19: 113-122.
11. Schwab ME. Nogo and axon regeneration. Curr Opin Neurobiol 2004; 14: 118-124.

12. Baumann MD, Kang CE, Tator $\mathrm{CH}$, Shoichet MS. Intrathecal delivery of a polymeric nanocomposite hydrogel after spinal cord injury. Biomaterials 2010; 31: 7631-7639

13. Kang CE, Poon PC, Tator CH, Shoichet MS. A new paradigm for local and sustained release of therapeutic molecules to the injured spinal cord for neuroprotection and tissue repair. Tissue Eng Part A 2009; 15: 595-604

14. Jimenez HMC, Tsai EC, Tator CH, Shoichet MS. Novel intrathecal delivery system for treatment of spinal cord injury. Exp Neurol 2003; 182: 300-309.

15. Jimenez HMC, Tator $\mathrm{CH}$, Shoichet MS. Injectable intrathecal delivery system for localized administration of EGF and FGF-2 to the injured rat spinal cord. Exp Neurol 2005; 194: 106-119.

16. Dunn RL, Tipton AJ, Southard GL and Rogers JA. Biodegradable Polymer Composition 1997. US Patent [5599552].

17. Chu FM, Jayson $M$, Dineen $M K$, Perez $R$, Harkaway $R$ and Tyler RC. A clinical study of $22.5 \mathrm{mg} \mathrm{La}$ - 2550: A new subcutaneous depot delivery system for leuprolide acetate for the treatment of prostate cancer. J. Urol. 2002; 168: 1199-1203.

18. Dunn RL, Garrett JS, Ravivarapu H and Chandrashekar $B L$. Polymeric delivery formulations of leuprolide with improved efficacy. 2003: US Patent, 6: 565-874.

19. Royals MA, Fujita SM, Yewey GL, Rodriguez J, Schultheiss PC and Dunn RL. Biocompatibility of a biodegradable in situ forming implant system in rhesus monkeys. J. Biomed. Mater. Res. 1999; 45: 231-239

20. Graham $P D$, Brodbeck $K J$ and McHugh AJ. Phase inversion dynamics of PLGA solutions related to drug delivery. J. Control. Release. 1999; 58: 233-245

21. Yan S, Wang T, Feng L, Zhu J, Zhang K, Chen X, Cui L, Yin J. Injectable in situ self-cross-linking hydrogels based on poly (L-glutamic acid) and alginate for cartilage tissue engineering. Biomacromolecules.2014; 15(12): 4495-4508.

22. Zheng L, Jiang $X$, Chen $X$, Fan $H$, Zhang $X$. Evaluation of novel in situ synthesized nano-hydroxyapatite/collagen/ alginate hydrogels for osteochondral tissue engineering. Biomed Mater. 2014; 9(6): 065004. doi: 10.1088/17486041/9/6/065004.

23. Lambert WJ, Peck KD. Development of an in situ forming biodegradable poly-lactide-co-glycolide system for the controlled release of proteins. J. Control Release 1995; 33: 189-195.

24. Ahmed T. Approaches to develop PLGA based in situ gelling system with low initial burst. Pak J Pharm Sci. 2015; 28(2): 657-665. 